\title{
Occurrence of Vibrio cholerae in fish and water from a reservoir and a neighboring channel in Ouagadougou, Burkina Faso
}

\author{
Oumar Traoré ${ }^{1,2,3}$, Outi Martikainen ${ }^{3}$, Anja Siitonen ${ }^{3}$, Alfred S Traoré ${ }^{1}$, Nicolas Barro ${ }^{1}$, Kaisa Haukka ${ }^{3,4}$ \\ ${ }^{1}$ Laboratoire de Biologie Moléculaire d'Epidémiologie et de Surveillance des Bactéries et Virus Transmis par les \\ Aliments. CRSBAN / Département de Biochimie-Microbiologie, UFRSVT-Université de Ouagadougou, \\ Ouagadougou, Burkina Faso \\ ${ }^{2}$ National Laboratory of Public Health, Ouagadougou, Burkina Faso \\ ${ }^{3}$ Bacteriology Unit, Department of Infectious Disease Surveillance and Control, National Institute for Health and \\ Welfare (THL), Helsinki, Finland \\ ${ }^{4}$ Department of Food and Environmental Sciences, University of Helsinki, Finland
}

\begin{abstract}
Introduction: Vibrio cholerae is a human pathogen and natural inhabitant of aquatic environments. In this study, we surveyed the occurrence of $V$. cholerae in fish harvested from a reservoir that receives discharges from the population in Ouagadougou through several channels. Methodology: A total of 238 fish and 80 water samples were analyzed for the presence of $V$. cholerae.

Results: Altogether, $13 \mathrm{~V}$. cholerae strains were isolated. They were all identified as non-O1/non-O139 V. cholerae without the ctxA gene. The strains were mostly susceptible to the antimicrobials tested.

Conclusion: Although no strains of epidemic $V$. cholerae serotypes were encountered, it is important to monitor the microbiological quality of this extensively used water resource and its fish.
\end{abstract}

Key words: channel; fish; Ouagadougou; reservoir; Vibrio cholerae; water.

J Infect Dev Ctries 2014; 8(10):1334- 1338. doi:10.3855/jidc.3946

(Received 06 July 2013 - Accepted 02 May 2014)

Copyright $(\underset{C}{2014}$ Traoré et al. This is an open-access article distributed under the Creative Commons Attribution License, which permits unrestricted use, distribution, and reproduction in any medium, provided the original work is properly cited.

\section{Introduction}

Human infections caused by microorganisms transmitted by fish or an aquatic environment are quite common, depending on the season, the patient's contact with fish or the environment, dietary habits, and the immune system status of the exposed individual [1]. Infection rates often peak after storms, floods, or sewage spills that transfer contaminated effluent to aquatic ecosystems [2]. Vibrios are abundant in aquatic environments, where they are found free-living in water or in association with plankton. Vibrios favor higher water temperature; consequently, the outbreaks are more frequent during the warmer season $[3,4]$. One of the most dangerous gastroenteric infections is cholera. Epidemic cholera is caused by enterotoxin-producing $V$. cholerae of serogroups $\mathrm{O} 1$ and O139. Cholera vibrios are commonly transmitted to humans through ingestion of contaminated food or water, and the disease occurs mainly in developing countries with inadequate sanitation [5-7]. Studies have suggested that fish may act as reservoirs and vectors of $V$. cholerae [8]. While an estuarine environment represents an ideal setting for the survival and persistence of $V$. cholerae, cholera has also become endemic in arid and inland areas of Africa [9] such as Burkina Faso [10]. V. cholerae strains of non-O1/non-O139 serotypes can cause diarrheal symptoms and extraintestinal infections in humans [11]. Therefore, environmental monitoring for the presence of $V$. cholerae and other Vibrio species with pathogenic potential is important, as it can identify the potential sources of infections.

In Ouagadougou, the capital of Burkina Faso, many channels have been built to drain water off during the rainy season. People living next to the channels use them as a bin, throwing in a great deal of rubbish, which decreases the hygienic quality of the channel water. Yet, these water sources are used for fishing, bathing, other domestic activities, and irrigation of vegetables, thus increasing the risk of human infections. Local fishing activities provide income and are increasing due to the construction of 
many new reservoirs. In this study, we concentrated on one of the reservoirs located in the middle of the city of Ouagadougou, Barrage de Tanghin, and on one of the channels running close to it. The reservoir's water capacity is approximately 7 million $\mathrm{m}^{3}$ and it receives discharges of the city's untreated sewage, human waste, and runoff, which increases during the rainy season. Also, the hospital of Ouagadougou is located near the reservoir; the channel into which its wastewater flows is less than $50 \mathrm{~m}$ from the reservoir. During the rainy season, the channels often overflow and the water spreads to larger areas, posing a potential health risk to the city's inhabitants. In this study, we report on the discovery of $V$. cholerae in the water and fish from the Tanghin Reservoir and its neighboring channel.

\section{Methodology}

\section{Sampling}

The most important fish species in the reservoir is tilapia (Oreochromis niloticus). A total of 238 tilapias, with an average length of $12 \mathrm{~cm}$, were collected within a period of six months (March to August 2010), 228 from the Tanghin Reservoir and 10 from a channel. All the fish were purchased alive from fishermen. Fish were transported to the laboratory and processed within four hours of collection. The outer surface of the killed fish was disinfected by wiping it with $70 \%$ ethyl alcohol for two minutes, washing it three times with sterile water. The intestine was removed aseptically by using a scalpel and was ground with a sterile mortar and pestle. A total of 80 water samples of $250 \mathrm{~mL}$ each were taken from the reservoir and the channel, using a disinfected ladle fixed to a long stick. Water samples were transported to the laboratory on ice and analyzed within two hours of collection. The water temperature was measured at the sampling site with a $\mathrm{pH}$ meter with a temperature probe (WTW PH330; Aqua Merik, St-Nicolas, Canada).

\section{Microbiological analyses}

Broth enrichment technique was used to enhance detection of Vibrio spp. First, $1 \mathrm{~g}$ of each crushed intestine sample was added to $9 \mathrm{~mL}$ of alkaline peptone water (APW; Liofilchem, Roseto degli Abruzzi, Italy) and incubated at $37^{\circ} \mathrm{C}$ for 24 hours. Water samples were highly turbid and thus $1 \mathrm{~mL}$ of sample was inoculated directly into $9 \mathrm{~mL}$ of alkaline peptone water and incubated at $37^{\circ} \mathrm{C}$ for 24 hours. In both cases, a loopful of enriched broth was then streaked on thiosulfate-citrate-bile salts-sucrose agar (TCBS; Oxoid Ltd., Basingstoke, England) and incubated at $37^{\circ} \mathrm{C}$ for 24 hours. Presumptive $V$. cholerae colonies on TCBS were flat, circular, yellow, and sucrose-fermenting. Strains grown from typical colonies were cultured on nutrient agar (Oxoid, Basingstoke, UK) and incubated at $37^{\circ} \mathrm{C}$ for 24 hours and then submitted to oxidase and catalase tests. Strains positive in these tests were confirmed to be $V$. cholerae by API 20E (BioMerieux, Marcy l'Etoile, France). The strains were conserved in heart infusion with $15 \%$ glycerol in the freezer and sent to Finland for further characterization. Serotyping was done using glass agglutination and the antisera against $\mathrm{O} 1$ polyvalent (both Inaba and Ogawa), O1 Inaba, O1 Ogawa, and O139 (Bengal) (Denka Seiken Co., Tokyo, Japan). For detection of hemolysis, the strains were grown on sheep blood agar plates incubated at $36^{\circ} \mathrm{C}$ overnight.

$D N A$ extraction and polymerase chain reaction (PCR) for ctxA detection

To extract DNA, one or two colonies were suspended in $0.9 \% \mathrm{NaCl}$ solution and centrifuged at $3000 \mathrm{~g}$ for 5 minutes. The pellet was suspended in 100 $\mu \mathrm{L}$ of sterile water, boiled for 10 minutes, and centrifuged at $10,000 \mathrm{~g}$ for 1 minute. The supernatant was used as template in the PCR reactions. Each 25 $\mu \mathrm{L}$ PCR reaction contained $15.45 \mu \mathrm{L}$ of water, $2.5 \mu \mathrm{Ll}$ of Taq buffer (Applied Biosystems, Foster City, California, USA), $2.5 \mu \mathrm{L}$ of $\mathrm{MgCl}_{2}(25 \mathrm{mM}), 1.25 \mu \mathrm{L}$ of dNTP $(5 \mathrm{mM}), 2.5 \mu \mathrm{L}$ of primer ctxA-F and $2.5 \mu \mathrm{L}$ of primer ctxA-R, $0.3 \mu \mathrm{L}$ of Taq DNA-polymerase (5 $\mathrm{U} / \mu \mathrm{L}$ ) (Applied Biosystems, Foster City, California, USA), and $1 \mu \mathrm{L}$ of template. The PCR program consisted of 30 cycles of $94^{\circ} \mathrm{C}$ for 30 seconds, $60^{\circ} \mathrm{C}$ for 30 seconds, and $72^{\circ} \mathrm{C}$ for 30 seconds. Before the first cycle, the reaction mixture was heated at $94^{\circ} \mathrm{C}$ for 5 minutes; after the last cycle, the final extension was performed at $72{ }^{\circ} \mathrm{C}$ for 10 minutes. The control strains were $V$. cholerae RHV $5578 \mathrm{O} 1$ Inaba El Tor (UK NEQAS 8032), V. cholerae RHV 5822 O1 Ogawa El Tor (UK NEQAS 9668), $V$. cholerae RHV 5654 nonO1/non-O139 (UK NEQAS 9018), and Escherichia coli RHE 6715 (ATCC 25922) as a negative control. PCR products were run on $1.5 \%(\mathrm{wt} / \mathrm{vol})$ agarose gel to resolve the amplified products, which were visualized under UV light after ethidium bromide staining.

\section{Antimicrobial susceptibility testing}

Antimicrobial susceptibility patterns were tested with an epidemiologic antimicrobial panel of ampicillin $(10 \mu \mathrm{g})$, chloramphenicol $(30 \mu \mathrm{g})$, 
streptomycin $(10 \mu \mathrm{g})$, sulphonamide $(300 \mu \mathrm{g})$, tetracycline $(30 \mu \mathrm{g})$, trimethoprim $(5 \mu \mathrm{g})$, ciprofloxacin $(5 \mu \mathrm{g})$, gentamicin $(10 \mu \mathrm{g})$, nalidixic acid $(30 \mu \mathrm{g})$, cefotaxime $(5 \mu \mathrm{g})$, mecillinam $(10 \mu \mathrm{g})$, and imipenem $(10 \mu \mathrm{g})$ (Oxoid Ltd., Basingstoke, Hampshire, UK) using the disk diffusion method and following the EUCAST guidelines (http://www.eucast.org). E. coli ATCC 25922 was used as a control.

\section{Results}

A total of 238 fish, 25 reservoir water, and 55 channel water samples were collected and processed. From these, 78 sucrose-fermenting bacterial colonies were obtained, of which 18 were confirmed to be $V$. cholerae by the API test (Table 1). Of the $V$. cholerae strains, 15 were isolated - mainly from fish - between March and May, which corresponds to the warm season. During the raining season, only 3 strains were isolated in August from the channel water. The measured water temperature did not vary according to the season, being on average $30.5^{\circ} \mathrm{C}\left( \pm 1.5^{\circ} \mathrm{C}\right)$.

Thirteen of the strains remained alive for further characterization. None of them reacted with $\mathrm{O} 1$ or O139 antisera and they also lacked the $\operatorname{ctxA}$ gene tested for by PCR. However, all of them were hemolysis positive on blood agar. Six fish isolates and one water isolate were resistant to ampicillin, one fish isolate was intermediate to streptomycin, and one fish isolate was intermediate to sulphonamide, but otherwise the isolates were sensitive to the tested antimicrobials.

\section{Discussion}

$V$. cholerae was isolated from 18 of the $318(6 \%)$ fish and water samples we studied. This prevalence may actually be an underestimate, because upon exposure to an unfavourable environment, vibrios persist by entering a viable but nonculturable (VBNC) state [12]. All the $V$. cholerae strains we serotyped were non-O1/non-O139, and none of them contained the $\operatorname{ctxA}$ gene coding for the cholera toxin A subunit. Although organisms of the $\mathrm{O} 1$ serogroup are frequently isolated from aquatic environments, most of the environmental $\mathrm{O} 1$ isolates do not produce cholera toxin, to which the clinical state of cholera is principally attributed [13]. The absence of $V$. cholerae $\mathrm{O} 1$ in our samples may be due to the high prevalence of non-O1/non-O139 strains, which are believed to be indigenous members of the aquatic ecosystem and which can prevent isolation of the truly pathogenic strains [14]. Holding samples from freshwater ecosystems at an ambient temperature ranging from $31^{\circ} \mathrm{C}$ to $35^{\circ} \mathrm{C}$ for 20 hours before processing has been found to selectively increase the number of culturable vibrios [15].

Although the Vibrio strains isolated in our study were not of the serotypes causing cholera, they may still cause sporadic cases of watery diarrhea and inflammatory enterocolitis. There is also a risk for skin infections or life-threatening systemic infections, especially in children or in other subjects with immune-compromising factors, from swimming in the water [11]. Different Vibrio species have been

Table 1. Isolation of Vibrio cholerae from fish, Barrage de Tanghin reservoir and channel water between March and August 2010

\begin{tabular}{|c|c|c|c|c|}
\hline Period & Type of sample & $\begin{array}{c}\text { No. samples } \\
\mathrm{n}=318\end{array}$ & $\begin{array}{l}\text { No. V. cholerae isolates }(\%) \\
\mathrm{n}=18\end{array}$ & API profiles \\
\hline \multirow[t]{2}{*}{ March } & Fish & 29 & $5(17 \%)$ & 5347124 \\
\hline & Reservoir water & 10 & $1(10 \%)$ & 5347124 \\
\hline April & Fish & 30 & $3(10 \%)$ & $5147124 *, 5307124$ \\
\hline May & Fish & 47 & $5(11 \%)$ & $5346124 * *, 5347124$ \\
\hline \multirow[t]{3}{*}{ June } & Fish & 31 & 0 & - \\
\hline & Reservoir water & 5 & 0 & - \\
\hline & Channel water & 15 & 0 & - \\
\hline July & Fish & 24 & 0 & - \\
\hline
\end{tabular}

* For two isolates; ** For four isolates 
detected in seafood meant for human consumption [16]. In Israel, $V$. cholerae non-O1/non-O139 were isolated from the intestines of most of the fish species sampled [8].

Temperature and salinity of the environment have been reported to be the major parameters influencing the dynamics of $V$. cholerae [17]. In our study, $V$. cholerae was isolated more often during the warm period, which included March, April and May, although no apparent temperature change in the water was detected. Unlike most vibrios, $V$. cholerae does not require $\mathrm{NaCl}$ to grow [9], which probably enhances its survival and competitiveness against other vibrios in freshwater environments such as the Tanghin Reservoir. In the future, global warming might create new favourable environments for $V$. cholerae and increase its incidence in vulnerable areas [3].

The high prevalence of $V$. cholerae in the channel water in Ouagadougou is not surprising, since channels receive sewage from local settlements and from the hospital, and thus contain human pathogens. That $V$. cholerae was also isolated from the reservoir water is worrisome, because this water is used for irrigation of vegetables among other uses. Many similar reservoirs are used as a source of potable water in other towns in Burkina Faso. In a recent study in Nigeria, animal manure was found to contain $V$. cholerae $\mathrm{O} 1$ [18]. Especially during heavy rains, the pathogens can be washed to the rivers and contaminate the drinking water used in the countryside as well as the irrigation water. For instance, contaminated river water was claimed to have transported cholera vibrios from the outbreaks or sporadic cases in neighboring countries to Azerbaijan [7].

Alarmingly, V. cholerae $\mathrm{O} 1$ variant with reduced susceptibility to ciprofloxacin has been spreading in western Africa in recent years [19], but the environmental vibrios we isolated were largely sensitive. Half of our $V$. cholerae isolates were resistant to ampicillin. This is in agreement with a study recently conducted in South Africa, where ampicillin resistance was a common finding [20].

\section{Conclusions}

Our work demonstrates that fish and reservoir and channel water in Ouagadougou, Burkina Faso, harbor $V$. cholerae. No cholera vibrio serotypes were isolated in our study; however, other vibrios can potentially cause sporadic gastroenteritis and serious diseases. Their presence indicates a need for quality microbiological surveillance of fish products and water, which is used for various human activities and for irrigation of fresh vegetables.

\section{Acknowledgements}

The study was funded by the Academy of Finland grant 122600, a collaboration between the Finnish National Institute for Health and Welfare (THL) and CRSBAN/University of Ouagadougou, Burkina Faso. We thank the personnel of Bacteriology Unit at THL for help in serotyping the isolates.

\section{References}

1. Novotny L, Dvorska L, Lorencova A, Beran V, Pavlik I (2004) Fish: a potential source of bacterial pathogens for human beings. Vet Med Czech49: 343-358.

2. Altekruse SF, Cohen ML, Swerdlow DL (1997) Emerging foodborne diseases. Emerg InfectDis3: 285-293.

3. Paz S (2009) Impact of temperature variability on cholera incidence in southeastern Africa, 1997- 2006. Ecohealth6: 340-345.

4. Iwamoto M, Ayers T, Mahon BE, Swerdlow DL (2010) Epidemiology of seafood- associated infections in the United States. Clin Microbiol Rev23: 399-411.

5. Thompson FL, Iida T, Swings J (2004) Biodiversity of Vibrios. Microbiol Mol Biol Rev68: 403-431.

6. Mason PR (2009) Zimbabwe experiences the worst epidemic of cholera in Africa. J Infect Dev Ctries3: 148-151. doi:10.3855/jidc. 62 .

7. Gurbanov SH, Akhmadov R, Shamkhalova G, Akhmadova S, Haley BJ, Colwell RR, Huq A (2011) Occurence of Vibrio cholerae in municipal and natural waters and incidence of cholera in Azerbaijan. Ecohealth 8: 468-477.

8. Senderovich Y, Izhaki I, Halpern M (2010) Fish as reservoirs and vectors of Vibrio cholerae. PLoS ONE: e8607.

9. Kaper JB, Morris JG Jr, Levine MM (1995) Cholera. Clin MicrobiolRev8: 48-86.

10. Kyelem GC, Bougouma A, Thiombiano SR, Salou-Kagoné AI, Sangaré L, Ouédraogo R (2011) Epidémie de cholera au Burkina Faso en 2005: aspects épidémiologiques et diagnostiques. Pan African Med J 8: 1-6.

11. Tantillo GM, Fontanarosa M, Di Pinto A, Musti M (2004) Updated perspectives on emerging vibrios associated with human infections. Lett Appl Microbiol 39: 117-126.

12. $\mathrm{Xu}$ HS, Roberts N, Singleton L, Attwell LW, Grimes DJ, Colwell RR (1982) Survival and viability of non culturable Escherichia coli and Vibrio cholerae in estuarine and marine environment. Microbiol Ecol8: 313-323.

13. Igbinosa EO, Okoh AI (2008) Emerging Vibrio species; an unending threat to public health in developing countries. Res Microbiol159: 495-506.

14. Mishra A, Taneja N, Sharma M (2011) Environmental and epidemiological surveillance of Vibrio cholerae in a choleraendemic region in India with fresh water. J Appl Microbiol112: 225-237.

15. Alam M, Sadique A, Nur-A-Hasan, Bhuiyan NA, Nair GB, Siddique AK, Sack DA, Ahsan S, Huq A, Sack RB, Colwell RR (2006) Effect of transport at ambient temperature on detection and isolation of Vibrio cholerae from environmental samples.Appl Environ Microbiol 72: 2185-2190.

16. Schärer K, Savioz S, Cernela N, Saegesser G, Stephan R (2011) Occurrence of Vibrio spp. in fish and shellfish collected from the Swiss market. J Food Prot 74: 1345-1347. 
17. Jiang SC, Fu W (2001) Seasonal abundance and distribution of Vibrio cholerae in coastal waters quantified by a $16 \mathrm{~S}-23 \mathrm{~S}$ intergenicspacer probe. Microbiol Ecol 42: 540-548.

18. Abakpa GO, Umoh VJ, Ameh JB (2013) Occurrence of Vibrio cholerae in some households engaged in livestock farming in some parts of Zaria, Nigeria. Adv Microbiol 3: 128-131.

19. Quilici ML, Massenet D, Gake B, Bwalki B, Olson M (2010) Vibrio cholerae $\mathrm{O} 1$ variant with reduced susceptibility to Ciprofloxacin, Western Africa. Emerg Infect Dis16: 18041805.

20. Okoh AI, Igbinosa EO (2010) Antibiotic susceptibility profiles of some Vibrio strains isolated from fresh water final effluents in a rural community of the Eastern Cape Province of South Africa. BMC Microbiol10: 143-148.

\section{Corresponding author}

Oumar Traoré

Biologie Moléculaire d'Epidémiologie et de Surveillance des Bactéries et Virus Transmis par les Aliments, Centre de Recherche en Sciences Biologiques Alimentaires et Nutritionnelles,

Département de Biochimie Microbiologie

UFR-SVT/Université de Ouagadougou

03 B.P. 7021 Ouagadougou 03, Burkina Faso

Phone: + 22670784266

Email: marrou4@yahoo.fr

Conflict of interests: No conflict of interests is declared. 